\title{
Disease, Dysfunction, and Synthetic Biology
}

Holm, Sune Hannibal

Published in:

Journal of Medicine and Philosophy

DOI:

10.1093/jmp/jhu025

Publication date:

2014

Document version

Early version, also known as pre-print

Citation for published version (APA):

Holm, S. H. (2014). Disease, Dysfunction, and Synthetic Biology. Journal of Medicine and Philosophy, 39(4), 329-345. https://doi.org/10.1093/jmp/jhu025 


\title{
Disease, Dysfunction, and Synthetic Biology
}

\author{
SUNE HOLM* \\ University of Copenhagen, Copenhagen, Denmark \\ *Address correspondence to: Sune Holm, PhD, Department of Media, Cognition, and \\ Communication, University of Copenhagen, Karen Blixens Vej 4, 2300 Copenhagen, \\ Denmark. E-mail: suneh@hum.ku.dk
}

\begin{abstract}
Theorists analyzing the concept of disease on the basis of the notion of dysfunction consider disease to be dysfunction requiring. More specifically, dysfunction-requiring theories of disease claim that for an individual to be diseased certain biological facts about it must be the case. Disease is not wholly a matter of evaluative attitudes. In this paper, I consider the dysfunction-requiring component of Wakefield's hybrid account of disease in light of the artifactual organisms envisioned by current research in synthetic biology. In particular, I argue that the possibility of artifactual organisms and the case of oncomice and other bred or genetically modified strains of organism constitute a significant objection to Wakefield's etiological account of the dysfunction requirement. I then develop a new alternative understanding of the dysfunction requirement that builds on the organizational theory of function. I conclude that my suggestion is superior to Wakefield's theory because it (a) can accommodate both artifactual and naturally evolved organisms, (b) avoids the possibility of there being a conflict between what an organismic part is supposed to do and the bealth of the organism, and (c) provides a nonarbitrary and practical way of determining whether dysfunction occurs.
\end{abstract}

Keywords: disease, functions, health, organisms, synthetic biology

\section{INTRODUCTION}

A persistent issue in the philosophy of medicine concerns the problem of defining disease. Traditionally, analyses take one of three forms. Naturalists (Kendell, 1975; Boorse, 1976b, 1977, 1997; Scadding, 1990) claim that disease shouldbedefined in descriptivebiologicalterms. Normativists (Margolis, 1976; 
Goosens, 1980; Sedgwick, 1982; Engelhardt, 1986) argue that disease judgments express views about the value and desirability of the states in question. Finally, hybrid views (Reznek, 1987; Caplan, 1992; Wakefield, 1992) suggest that a satisfactory analysis of the concepts of health and disease has both a naturalistic and an evaluative component. All three approaches face significant challenges, and it has been suggested that instead of being preoccupied with finding the correct definition and analysis of these concepts, we should instead focus our effort on providing a "philosophical explication" of disease (Schwartz, 2004, 2007a) or heed a distinction between state descriptions and normative claims when considering controversial medical cases such as deafness and alcoholism (Ereshefsky, 2009). It is the traditional question that will make up the framework of this paper. In particular, I will focus on what Schwartz (2007a, 2007b) calls the dysfunction requirement, according to which biological dysfunction is necessary for disease. Both Boorse and Wakefield's criteria of disease refer to biological dysfunction. However, their understanding of the dysfunction requirement differs in that they accept different theories of biological function. In this paper, I discuss Wakefield's description of the dysfunction requirement in terms of the etiological theory of biological function. My criticism of Wakefield is based on two cases that I think reveal some significant shortcomings of Wakefield's characterization of the dysfunction requirement.

One problem arises when considering disease in the context of current research in synthetic biology. Synthetic biologists aim to design and produce novel organismic parts, processes, and systems tailor-made to serve human purposes. However, due to their lack of evolutionary history, such possible, though not as yet existing, artifactual organisms created "from scratch" will fail to satisfy the definition of dysfunction proposed by Wakefield. ${ }^{1}$ Another problem arises in the context of transgenic and artificially bred organisms. For example, Wakefield's approach entails the implausible, and arguably repugnant, conclusion that oncomice, engineered and bred for a genetic defect that leads to an extremely high incidence of cancer, will meet the dysfunction requirement if they develop tumors. I claim that these problem cases constitute a strong objection to accepting Wakefield's etiological account of the dysfunction requirement. Finally, I propose a new alternative account of disease in terms of the organizational account of biological teleology and normative function (Mossio, Saborido, and Moreno, 2009; Saborido, Mossio, and Moreno, 2011). According to the organizational account, the function of organismic parts and processes is conferred on them by their current role in the selfmaintaining organization of the organism. I suggest that the dysfunction requirement should be stated in terms of the organizational account of normative function in order for it to provide an adequate characterization of the problem cases discussed. 
In sections II and III, I present Wakefield's understanding of the dysfunction requirement and the case for the etiological theory of biological function to which he appeals. In section IV, I present the two cases, reflection on which, I argue, reveals a flaw in the etiological version of the dysfunction requirement. In section V, I present the organizational account of normative organismic function, and in section VI, I show how it enables accounts of disease, which include the dysfunction requirement, to accommodate naturally evolved as well as artifactual and bred and engineered organisms.

\section{WAKEFIELD'S THEORY OF DISEASE}

Wakefield states his hybrid criterion of disease thus:

A condition is a disorder if and only if (a) the condition causes some harm or deprivation of benefit to the person as judged by the standards of the person's culture (the value criterion), and (b) the condition results from the inability of some internal mechanism to perform its natural function, wherein a natural function is an effect that is part of the evolutionary explanation of the existence and structure of the mechanism (the explanatory criterion) (Wakefield 1992, 384).

In the explanatory criterion, Wakefield characterizes the dysfunction requirement in terms of the etiological account of biological function, so let us look at what seems to be the main argument for accepting it.

\section{WHY ACCEPT THE ETIOLOGICAL THEORY? ${ }^{2}$}

The case in favor of the etiological theory of function can be summed up in terms of its ability to satisfy three desiderata about naturalistic function ascriptions to organismic traits:

1. Citing the function of an item explains why it exists;

2. Function ascriptions are normative in the sense that, when we say that the function of an item is to do F, we say something about what it is supposed to $\mathrm{do}^{3}$;

3. Not just any effect of an item is its function, so it must be possible to discriminate between an item's "accidental" effects and its function.

To illustrate, consider the case of the human heart. In accordance with biological and ordinary usage, the etiological theory claims that the function of the human heart is to pump blood. By determining the function of the human heart on the basis of its history of natural selection, we can say the following: human hearts exist because, by pumping blood, hearts have made a causal contribution to the differential survival and reproduction of organisms that have them. Furthermore, we can say that even if making a thumping sound has occasionally contributed to the survival and reproduction of a human 
being, it is not a function of the heart because there has not been natural selection for that effect. And, finally, because hearts and other organismic traits have a natural selection history, we can make sense of the idea that biological function ascriptions state what the function bearer is for. A heart ought to pump blood because hearts are selected for this effect. A heart that is not capable of pumping blood is not functionless, but dysfunctional, because it exists for pumping blood, that is to say, because it has a normative function.

Advocates of the etiological approach often point out that the single most problematic implication of alternative approaches is that they do not account for the normative dimension of biological function. Let me briefly sketch the claims and criticisms of three significant dispositional accounts, which, in contrast with etiological accounts, claim that the function of an item is a causal contribution that it actually makes to some capacity or goal of the system.

One of the most influential dispositional approaches is Cummins' (1975) systemic capacity account. Systemic capacity functions are relative to a salient capacity $\mathrm{C}$ of a system $\mathrm{S}$ that we want to understand in terms of a "functional analysis" in which a system and its parts are specified. In the systemic capacity account, the function of a part X of a system $S$ is to $F$ if and only if $X$ has the capacity to F and X's capacity to F causally contributes to S's capacity to C. ${ }^{4}$ Although there might be contexts in which systemic capacity functions are useful for understanding a complex system, such functions do not say what their bearers are supposed to do. The systemic capacity account will ascribe functions to all sorts of items that we do not take to be supposed to do anything at all. Thus, the systemic account will arguably ascribe the function of causing earthquakes to tectonic plates (Neander, 1991) and take it to be a function of clouds to make rain to fill rivers and streams (Millikan, 1989). ${ }^{5}$

Boorse (1976a, 2002) has suggested that the proper function of an organic part is its actual causal contribution to the goal of the organism, which, given the way in which organisms are disposed to adjust their activities in order to maintain life, he suggests is survival and reproduction. However, Boorse's statistical account of normal function seems unsatisfactory. ${ }^{6}$ Boorse introduces a norm for the function of a trait in terms of the statistically normal contribution to survival and reproduction that the trait has within the relevant class of organisms (Boorse, 1976a,b). However, the statistical account of normativity is problematic because it entails that, for example, eyes are only supposed to contribute to vision if that is what eyes actually do statistically speaking. A statistical norm is basically a descriptive claim, not a normative claim about what a trait is supposed to do. The problem can be illustrated by imagining a case in which most people suddenly went blind. The statistical account implies that in such a case human eyes would cease to have the function of seeing. However, as Neander $(1991,182)$ points out, 
the correct description of this kind of case certainly seems to be that human eyes have the function of seeing, but a majority of them cease to perform their function properly.

A similar problem arises with respect to the propensity theory of Bigelow and Pargetter (1987). According to the propensity account of function, the function of a part of an organism, such as the human heart, is its disposition to enhance the chance of survival and reproduction, or the fitness, of the organism that has it. However, like Cummins and Boorse's accounts, the propensity theory is unable to equip biological functions with a normative aspect. As Neander points out, a dysfunctioning part does not dispose its bearer to survive and reproduce, but according to the propensity theory, this is not a case of a part that dysfunctions, but a case of a part that does not have a function at all (see Neander 1991, 183). For present purposes, the most important implication of the etiological theory is that, in addition to grounding the teleological aspect of functions, the theory arguably also grounds the normativity of functions.

We have seen that the etiological analysis of function is well suited for Wakefield's explanatory criterion of disease because, unlike its dispositional competitors, it can make sense of biological dysfunction. However, relying on the etiological account is, I will argue, problematic because of the consequences it has with regard to possible future products of synthetic biology and existing transgenic and bred organisms.

\section{DISEASE, ARTIFACTUAL ORGANISMS, AND ONCOMICE}

In this section, I will present a line of criticism of Wakefield's theory that is based on current work in synthetic biology. I argue that the possibility of artifactual organisms illustrates a problematic feature of understanding the dysfunction requirement in terms of the etiological account.

My focus will be on a problem that arises as a consequence of identifying the normative function of organismic parts with the effects for which they have been selected. The problem is that etiological theories sever the relation between normative function and the current causal powers of the function bearer. Here my aim is not to assess whether the etiological theory should be rejected as a theory of functions on the basis of this and other objections. Etiologists are well aware of the problem and (as we have seen in section III) their standard reply is that we cannot get, from any single theory of function, both normativity and a dispositional analysis that refers to the current causal capacities of the function bearer. Nevertheless, the historical aspect of the etiological theory results in a problematic consequence for Wakefield's explanatory criterion, and thus, in the next section, I will suggest that the explanatory criterion should be stated in terms of an alternative account of normative function. But first I will present my criticism, and in order to do 
so it will be necessary to introduce the emerging field of synthetic biology and the notion of an artifactual organism.

\section{Synthetic Biology and Artifactual Organisms ${ }^{7}$}

One of the defining aims of synthetic biology is to develop the ability to rationally design and fabricate organic systems or parts of such systems that have no natural counterparts. ${ }^{8}$ Two approaches are standardly distinguished: a top-down approach that aims to create new forms of life by modifying extant life forms, and a bottom-up approach that aims to create living systems from nonliving materials ("from scratch").

The top-down approach is exemplified by synthetic genomics research, such as the widely reported project at the J. Craig Venter Institute. The ultimate goal of the synthetic genome approach is to develop a process that allows for large-scale production of microbial life, tailor-made to perform a wide range of useful functions, such as generating hydrogen for fuel or capturing excess carbon dioxide in the atmosphere.

In 2010, a group of researchers from the J. Craig Venter Institute published a widely reported article presenting how they had created the world's first chemically synthesized genome (see Gibson et al., 2010). The research group fabricated a copy of the genome of the microorganism Mycoplasma mycoides and inserted it into an already living cell that was stripped of its original genome. The resulting microorganism, the M. mycoides JCVI-syn1.0, is a living, self-replicating cell controlled by a genome that has been spliced together by humans. It is worth emphasizing that the synthetic genome is a man-made copy of the genome of an already existing bacterium. Commenting on the result, one of the members of Venter's team remarked that:

With this approach we now have the ability to start with a DNA sequence and design organisms exactly like we want. (...) We can get down to the very nucleotide level and make any changes we want to a genome (Katsnelson, 2010).

The achievement of Venter's group means that it is now possible for humans to initiate a lineage of cells with genomes descended from a synthetic genome. An implication is that this will result in organisms and forms of life that have never existed before, and, depending on how we draw the distinction between modifications of existing life and the creation of entirely new forms of life, this may be technically true of Venter's organism. Thus, according to Preston (2008), there is a fundamental difference between synthetic biology and traditional biotechnology such as breeding and genetic engineering.

In every case of traditional biotechnology-even in the case of transgenic organisms-the genome on which the modification takes place is either the product of natural evolutionary processes or is the descendent of such a product. In every case in traditional biotechnology, there exists prior to the modification a viable organism 
on which the manipulation takes place. This is not the case in synthetic biology. Synthetic biology does not start with a viable genome and modify it. It starts afresh with bio-bricks [DNA sequences with a defined structure and function] possessing known properties. There is no existing genome that undergoes modification. In the current state of the technology, the synthetically engineered DNA sequences have all been inserted into existing single-celled organisms. The idea, however, is not to preserve properties of the existing bacteria with modified behaviour. It is to create an entirely new organism with DNA constructed in its entirety according to human plan. The products of synthetic biology do not borrow any genetic function from genomes produced by the historical evolutionary process. To the contrary, synthetic biology is guided by the idea of leaving evolution and existing genomes behind in order to do a better job of creation with human goals in mind (Preston, 2008, 33).

If Preston is right, then synthetic biology seems to present a challenge to the etiological theory of normative function similar to the challenge raised by the possibility of instant organisms widely discussed in the literature on functions. ' However, I find that Preston overstates the extent to which the synthetic organism, resulting from a process of synthesizing a naturally occurring genome and inserting it into an enucleated cell, presents a radical break with natural evolution.

First, I think it is questionable whether replacing the genome of a cell with a synthesized copy of another naturally occurring genome, despite the significance of the genome in the functioning of the synthetic cell, amounts to a radical break with evolution. After all, a large proportion of the synthetic cell is made up of other crucial parts from the original cell. Thus, all the subcellular structures (mitochondria, liposomes, etc.) necessary for vital processes, such as the metabolism of the synthetic cell, are not synthetic, but products of natural evolution.

Second, the synthesized genome in the synthetic cell created by Venter's group (except for a few "watermarks") is a copy of a naturally evolved genome and may therefore be considered a reproduction of a naturally existing genome, albeit with an extraordinary causal history. As a matter of fact, synthetic biologists recognize that it is unlikely that humans will be able to design a synthetic genome in the near future that is not, largely, a copy of a naturally occurring genome with some useful modifications. Despite the impressive technical achievements in synthesis and transplantation of genomes, there is still a "very poor ability to de novo design (writing) genomes" (Porcar et al., 2011, 2). Thus, I submit that while synthetic genomics may shortcut natural evolution in various ways by creating organisms with genomes unlikely to arise through natural evolution, it is not likely to produce synthetic organisms that constitute a radical break with ordinary evolutionary processes. ${ }^{10}$

Preston's description of synthetic biology fits the potential products of the bottom-up approach better. Bottom-up synthetic biology is exemplified by protocell research. Protocells are characterized as microscopic, self-organizing, evolving entities that spontaneously assemble from simple organic and inorganic materials. In the words of Bedau and Parke (2009, 1): 
Protocells are alive; they are similar to single-celled organisms like bacteria, in that they grow by harvesting raw materials and energy from their environment and converting it into forms they can use, they sense and respond to their environment and take steps to keep themselves intact and pursue their needs, and they reproduce and ultimately evolve (Bedau and Parke, 2009, 1).

One of the leading synthetic biology researchers, Martin Hanczyc, provides the following description of the creation of simple protocells:

The construction of a protocell begins with different types of both natural and synthetic molecules. The chemical and physical properties of individual molecules govern their formation into higher-order structures, such as synthetic cell membranes. The structures are collections of hundreds of millions of molecules that then possess properties not present in the individual molecules. Some structures, such as synthetic protocells, resemble roughly the architecture of living cells with the same size scale. (...) Due to the method of construction, the protocell may be programmed to contain various chemistries and metabolisms, from simple to complex. The protocell can therefore be programmed to consume or produce selectively in a given environment (Hanczyc, 2011, 27).

The bottom-up approach of protocell research may very well enable synthetic biologists to create a minimal living system from nonliving chemical components (i.e., "from scratch"). Artifactual organisms will be self-assembling and self-organizing systems, which are complex enough to instantiate crucial life processes such as metabolism, replication, and the capacity to evolve without relying on components of natural life forms. Furthermore, as Hanczyc points out, protocells may be programmed to respond to their environment in useful ways and, thus, serve as instruments, for example, for consuming certain unwanted substances (e.g., CO2) and/or producing other valued substances that may be used for clean energy production or in pharmaceuticals.

In the rest of this paper, I will focus on the possibility of artifactual organisms. Unlike a synthetic organism, an artifactual organism is made from scratch in the way envisioned by protocell research without using material from extant life forms.

\section{The Problem of Artifactual Organisms}

The possibility of artifactual organisms provides an interesting challenge to any definition of the dysfunction requirement that appeals to an etiological theory of function. Consider Arto, an artifactual organism produced along the lines suggested by protocell researchers, except that it has not been programmed to do anything, but is able to survive and reproduce in a petri dish by virtue of having a physical boundary delineated by a membrane, the capacity to transform energy and grow (a metabolic network inside the boundary), and a genome that controls metabolism and enables replication. ${ }^{11}$ 
One of Arto's traits is possession of a membrane, which plays a crucial role for Arto's survival and reproduction, because it acts as a selective filter that allows only certain kinds of matter to enter and exit the cell. For example, some of the matter allowed to enter is transformed by Arto's metabolism to be used for, among other things, the growth and maintenance of the membrane itself. Imagine that at some point Arto's membrane is "damaged" in such a way that it is no longer able to control the inflow and outflow of matter to the degree required for Arto's survival, including Arto's capacity for maintaining the membrane itself. ${ }^{12}$

The etiological theory entails that Arto's membrane does not have the normative function of filtering matter because Arto does not have a selection history, even if, in a purely descriptive sense, this is what Arto's membrane does. This means that, according to Wakefield's analysis, Arto's membrane is not dysfunctional when it ceases to control the flow of matter in and out of Arto. Arto's behavior merely changes in certain ways, but there is nothing wrong, and nothing can be wrong, with Arto or Arto's membrane. ${ }^{13}$

Wakefield's theory requires that he reject the claim that Arto satisfies the explanatory criterion when its membrane ceases to filter matter. It is impossible for Arto to dysfunction because it does not descend from a population of organisms that has been subject to natural selection. ${ }^{14}$ I will characterize Wakefield's theory as partial because it entails that there are possible scenarios in which some organismic systems will not have normative biological functions. Now, my claim is that we can make Wakefield's theory complete by revising the functional element of the explanatory criterion.

\section{The Problem of Oncomice}

Another problem facing Wakefield's theory concerns organisms with traits that have been selected for causing what clearly seems to be a defective state in the organism. Oncomice are mice that have been genetically modified such that they carry a gene, "the oncogene," which makes them highly susceptible to developing cancer and thus very useful for cancer research. ${ }^{15}$ The first oncomouse created by genetic modification may be considered to be a mutation, a new variant of mouse, that came to exist in a certain environment where the needs and desires of humans in general, and cancer researchers in particular, have a significant influence on the selection regime. In that environment, there has been selection of oncomice for their possession of the oncogene and its consequences for cancer development. Thus, like cultivated seeds, oncomice have a history of natural selection in which humans have played a significant role in determining the environment. ${ }^{16}$ This means that, according to the etiological theory, the function of the oncogene in oncomice is to cause cancer since cancer is both a consequence of the oncogene and the consequence for which there has been selection. Hence, on the etiological theory, contributing 
to the development of tumors is the normative function of oncogenes in oncomice.

Now, in the context of Wakefield's explanatory criterion, the fact that oncogenes are supposed to cause cancer entails that an oncomouse, whose oncogene performs its function, will not satisfy the explanatory criterion. Thus, Wakefield's theory implies that oncomice with cancer will not be diseased because they do not satisfy the dysfunction requirement. The problem generalizes to other cases concerning bred and genetically engineered animals, which have been selected for their genetic disposition to develop diseases. I contend that this is a highly objectionable consequence of Wakefield's explanatory criterion. In the next section, I will sketch an account of normative function that I think does a better job than the etiological theory when it comes to characterizing the functional element of Wakefield's explanatory criterion.

\section{AN ORGANIZATIONAL ACCOUNT OF ORGANISMIC FUNCTION}

I have argued that Wakefield's account of disease is unsatisfactory because it, by definition, excludes that possible artifactual organisms can be diseased and implies that oncomice are not diseased when they develop cancer. In this section, I will offer an analysis of organismic function, which better suits Wakefield's statement of the explanatory criterion. More specifically, I will argue that the organizational account of function developed by Christensen and Bickard (2002), Mossio, Saborido, and Moreno (2009), and Saborido, Mossio, and Moreno (2011) provides a coherent and plausible analysis of biological function that is able to ground the normative aspect of function ascriptions. According to the organizational approach, the teleological and normative aspects of biological function ascriptions are analyzed in terms of the organizational features of organisms and not with reference to their origin in natural evolution. In what follows, I will outline the main theses of the organizational approach, which I think will be adequate for the purposes of this paper. I will focus on the most recent account given by Saborido, Mossio, and Moreno (2011). ${ }^{17}$

Proponents of the organizational approach begin by pointing out that it is by virtue of being self-maintaining systems that organisms realize "the relevant causal regime in which the teleological and normative dimensions of functions can be adequately naturalized" (Saborido, Mossio, and Moreno, 2011, 592). Self-maintenance is characterized as a property of systems that are able to exert a causal influence on their surroundings in order to maintain (at least some of) the boundary conditions required for their own existence. A standard case of a self-maintaining system is a candle flame:

[A candle flame] maintains above combustion threshold temperature. It vaporizes wax into a continuing supply of fuel. In a standard atmosphere and gravitational 
field, it induces convection, which pulls in continuing oxygen and removes combustion products. A candle flame, in other words, tends to maintain itself; it exhibits self-maintenance (Bickhard, 2000).

Saborido, Mossio, and Moreno (2011) argue that the fact that a system maintains itself makes good sense of the claim that the system is teleological; it exists because of something it does. One case that seems to support this claim is a living cell, the paradigmatic case of a natural teleological system. Like Arto described in section IV, a living cell exists partly because of something it does. For example, cells produce their own physical boundary, their membrane, which facilitates the transportation of matter and energy necessary for the survival of the cell, including its capacity for generating and repairing the membrane. Perhaps surprisingly, the organizational account also claims that flames are teleological systems. By virtue of causing the combustion of gases in its vicinity, a flame continues to create the conditions under which it is capable of performing that very activity.

The fact that self-maintaining systems are teleological also confers a normative dimension on their activities. Because self-maintaining systems are causally responsible for producing some of the conditions necessary for their own existence, they are subject to norms of performance. There are certain effects that a cell or a flame is supposed to bring about in order for it to persist. In the words of Saborido, Mossio, and Moreno:

[The] mutual dependence between their existence and activity, which is specific to self-maintaining systems, provides an intrinsic and naturalized criterion to determine what norms the system, and its parts, are supposed to follow.

The conditions of existence of the system are here interpreted as the norms of its own activity: the flame must behave in a specific way, otherwise it would cease to exist (Saborido, Mossio, and Moreno, 2011, 593).

The organizational account provides an alternative and coherent way of understanding normative function in organic systems that does not rely on the artifact analogy and hence does not involve natural selection. The important conclusion is that, according to the organizational theory, self-maintenance is sufficient for teleology and normativity. In section VI, we will see how this feature of the organizational account plays out in a revised version of Wakefield's account of disease.

\section{REVISING THE EXPLANATORY CRITERION}

In order to present my alternative formulation of Wakefield's explanatory criterion, it will be helpful to render Wakefield's explanatory criterion thus:

Etiological Explanatory Criterion (EEC) Condition X is a disease of system $\mathrm{S}$ only if $\mathrm{X}$ results from the failure of a part or process $\mathrm{P}$ of $\mathrm{S}$ to perform its function $\mathrm{F}$, where $\mathrm{F}$ is an effect for which $\mathrm{P}$ has been naturally selected. 
We have seen that, according to the EEC, neither conditions that are realized by possible artifactual organisms, nor cancer in oncomice, will qualify as diseases. My suggestion is that the EEC is revised in terms of the organizational account of normative function:

Organizational Explanatory Criterion (OEC) Condition $\mathrm{X}$ is a disease of system $\mathrm{S}$ only if $\mathrm{S}$ is a differentially organized, self-maintaining system, and $\mathrm{X}$ compromises the ability of $\mathrm{S}$ to maintain itself. ${ }^{18}$

Before I present the features of the OEC that I think makes it superior to the EEC. I will briefly explain how the OEC precludes that simple dissipative structures such as candle flames can satisfy the factual requirement on disease. We would like to be able to claim that a candle flame cannot be diseased due to facts about it, not in virtue of sociocultural values. Furthermore, considering this question will also bring out in more detail how to understand normative function on the organizational theory.

My suggestion is that candle flames will not be able to satisfy the OEC because they are not organized in the following sense:

A self-maintaining system is organizationally differentiated if it produces different and localizable patterns or structures, each making a specific contribution to the conditions of existence of the whole organization (see Mossio, Saborido, and Moreno, 2009, 826).

That a candle flame is not an organizationally differentiated system is clear from the fact that it does not produce and regenerate mutually dependent substructures, whose integrated activity enables it to maintain itself. A flame merely consumes its components. In contrast, an organizationally differentiated system, paradigmatically a living cell, consists of a variety and hierarchy of mutually dependent material structures, whose coordinated activity enables the cell to maintain itself and, in turn, enables it to maintain those very structures. The relation between a cell and its membrane provides a good example of differentially organized self-maintenance. The cell membrane is a distinct substructure of the cell that filters the matter entering and exiting the cell. Furthermore, the membrane filters matter within certain parameters appropriate for the maintenance of the coordinated metabolic processes of the cell, which, in turn, maintain the membrane.

On the basis of these considerations, we can state the organizational account of function in terms of the case of the cell membrane: The membrane serves the function of filtering matter in the cell if and only if by filtering matter, the membrane contributes to the maintenance of the mutually dependent processes of the cell, and the membrane is itself produced and maintained in virtue of facilitating those processes. More formally, we can say that an organismic part or process $\mathrm{P}$ serves a function $\mathrm{F}$ in relation to a differentially organized system $S$ if and only if:

1. By doing F, P contributes to the maintenance of the organization $\mathrm{O}$ of $\mathrm{S}$;

2. $\mathrm{P}$ is produced and maintained in virtue of the organization $\mathrm{O}$ of $\mathrm{S} .{ }^{19}$ 
The normative function of an organismic part is thus determined in relation to the preservation of the organization of the system. Given the current environment, the mutual dependence of the parts and processes constituting the organism establishes norms of performance that its parts and processes are supposed to meet. In relation to these norms of performance, an alteration in the output of a part or process may be said to result in a dysfunction of the organismic system. A corollary of the organizational understanding of normative function is that a token organ does not dysfunction per se, when it fails to perform an activity for which its type has been selected. For example, if one of the kidneys in an organism ceases to filter the blood, this will only be a dysfunctional condition, if it results in an inadequate filtering of the blood in relation to the requirements of the web of mutually dependent processes that constitutes the organism. The kidney, that is incapable of performing the effect it has been naturally selected for, does not dysfunction on the organizational account. ${ }^{20}$

With this specification of the organizational theory in hand, consider first the problem case of Arto the artifactual organism. Revised in terms of the organizational account, Arto fulfils the OEC, despite Arto's lack of a natural selection history. For example, Arto's membrane can be said to have the regulation of inflow and outflow of matter as its normative function because it is partly by virtue of the causal regime, ensured by this effect of the membrane, that Arto is capable of the metabolic processes that enable it to maintain itself, including the production and repair of the membrane.

Second, cashing out the explanatory criterion in terms of organizational maintenance does not involve ascribing normativity to parts of the organism per se. The parts of an organism are only supposed to do something in relation to the viability of the whole system, not in relation to norms governing their own type. In contrast with the EEC, the OEC does not entail that the function of an organismic part or process can be supposed to do something, for example, what it has been naturally selected for, which conflicts with the viability of the organism. This means that the OEC avoids the conclusion that oncomice do not satisfy the explanatory criterion, when they develop tumors. ${ }^{21}$

Finally, it should also be noted that the OEC has the virtue of providing an answer to an epistemological problem facing the EEC. It is often quite hard to determine even the most recent selection pressures responsible for shaping the evolution of current organisms, and hence it can be quite difficult to determine whether or not an organismic part is dysfunctional in terms of its selection etiology. In turn this means that the EEC is likely to be practically inapplicable, when it comes to determining whether or not some condition is a disease. In contrast, the organizational account of organismic function makes it possible, even if challenging, to determine whether an organism satisfies the explanatory requirement on the basis of observation of its internal organization and activity in relation to its current environment. 
In sum, the alternative organizational version of the explanatory criterion (OEC) is superior to the EEC proposed by Wakefield because it (a) can accommodate both artifactual and naturally evolved organisms, (b) avoids the possibility of there being a conflict between what an organismic part is supposed to do and what is conducive to the self-maintenance of the organism, and (c) provides not only a nonarbitrary but also a practical way of verifying the presence of the factual component of disease.

\section{NOTES}

1. Throughout the paper, I will assume that nonsentient organisms can be diseased.

2. The literature on etiological theories of function is vast and addresses many issues that I cannot cover here. I will focus on what I take to be the virtues of etiological theory most often appealed to by those who defend it. Influential versions of the etiological theory can be found in Wright (1973), Millikan (1989), Neander (1991), Griffiths (1993), Godfrey-Smith (1994), and Mitchell (1995).

3. It is worth noting that when etiologists claim that functions are normative, they do not mean that functions supply agents with reasons for action (or belief). Nothing about what agents should do follows from the fact that leaves are supposed to contribute to photosynthesis.

4. For a vigorous and influential defense of the importance of Cummins's account in biological research, see Amundson and Lauder (1994).

5. For an interesting criticism of the claim that the systemic capacity account must ascribe the function of filling rivers and streams to clouds, see Davies (2001, 75).

6. For an excellent, recent discussion of Boorse's biostatistical theory of function, see Kingma (2010).

7. This section follows my presentation of synthetic biology in Holm (2012).

8. A similar characterization can be found in Douglas and Savulescu (2010). Another influential definition of synthetic biology is that it is "the design and construction of new biological parts, devices and systems, and the redesign of existing, natural biological systems for useful purposes" (SynBERC, 2012).

9. For elaborate discussion of how the etiological theory may deal with the alleged possibility of instantly created swamp organisms, see Millikan (1996) and Neander (1996). See Davidson (1987) for the original swamp case scenario. Boorse (1976a) raises the question concerning instantly created organism in his criticism of Wright (1973).

10. It is also important to note that synthetic organisms will be subject to natural selection. When they reproduce they will, in the appropriate circumstances, bring forth descendants that will constitute a population of organisms with members that vary with respect to traits that have an impact on fitness. See Sandler and Simons (2012) for similar criticisms of Preston.

11. My presentation relies on Flint (2012). For a recent overview of protocell research, see Rasmussen et al. (2009).

12. Strictly speaking, it will not be correct to assert that Arto's membrane is damaged when it ceases to filter matter because this presupposes that there is something it is supposed to do, and according to the etiological account there is not.

13. Arto's membrane might still be said to have a normative function according to the etiological account, but in that case it would be an artifactual function, that is, a function that has been conferred on the membrane by the intentions of the bioengineers who have created Arto. However, artifactual functions do not have the right sort of selection etiology to satisfy the dysfunction requirement as defined by Wakefield in the explanatory criterion.

14. Furthermore, as I have pointed out, Arto might replicate itself, and if the replication process results in a population that varies with respect to fitness-enhancing traits, Arto's descendants will come to possess normative functions. However, it is also worth observing that in case Arto's descendants do not come to form such a population, then their parts will not acquire normative functions. Thus, whether or not Arto's descendants will come to possess parts with normative functions depends on whether and when variation with respect to the right kind of traits arises in the population. 
15. See Delancey (2004) for a similar point made in connection with his criticism of the account of biological interests found in Varner (1998).

16. See Sperber $(2007,133)$ for an informative discussion of the case of cultivated seeds.

17. The following presentation is not intended as an argument for the organizational approach, which I will assume is a plausible, if somewhat overlooked, alternative to the well-known etiological and dispositional analyses of function. Mossio, Saborido, and Moreno (2009) and Saborido, Mossio, and Moreno (2011) provide a detailed defense of the view. For important developments and critical discussions of the organizational approach, see Schlosser (1998), McLaughlin (2001), and Delancey (2006). Saborido, Mossio, and Moreno (2011) distinguish two versions of the organizational account in terms of whether they focus on the self-reproduction of traits (Schlosser, 1998; McLaughlin, 2001) or on the organization of the system (Collier, 2000; Christensen and Bickard, 2002; Mossio, Saborido, and Moreno, 2009; Saborido, Mossio, and Moreno, 2011; Christensen, 2012).

18. Proponents of the organizational view suggest that we can determine whether a change in a part or process of the organism compromises its ability to maintain itself by comparing with alternative states that would be better or worse in this respect (see Christensen, 2012, 107). See Schwartz (2007b) for discussion of "the line-drawing problem" with regard to Wakefield and Boorse's theories.

19. My formulation is based on, but differs slightly from, Saborido, Mossio, and Moreno $(2011,594)$.

20. Let me emphasize that the point here is not to reject the value of an etiological understanding of dysfunction. The contention is that the organizational account of normative function and dysfunction is a genuine alternative that should be appealed to in a statement of the explanatory criterion.

21. In some cases, organisms exhibit suicidal behavior. It may seem plausible to claim that this kind of behavior has a normative function in relation to the reproduction of the species, even if it compromises the self-maintenance of individual members of the species. As I see it, this phenomenon concerns the sense in which organisms may be considered to be functional parts in the self-maintenance of higherlevel systems such as species and ecosystems. I leave discussion of this issue for another paper.

\section{ACKNOWLEDGMENTS}

I would like to thank the Danish Research Council (FKK) and Center for Synthetic Biology at University of Copenhagen funded by the UNIK research initiative of the Danish Ministry of Science, Innovation and Higher Education (0602-02164B) for supporting my research for this article. Also thanks to participants in the SYBHEL Project for helpful discussions.

\section{REFERENCES}

Amundson, R. and G. V. Lauder. 1994. Function without purpose: The uses of causal role function in evolutionary biology. Biology and Philosophy 9:443-69.

Bedau, M. and E. Parke, eds. 2009. The Ethics of Protocells: Moral and Social Implications of Creating Life in the Laboratory. Cambridge, MA: MIT Press.

Bickhard, M. H. 2000. Autonomy, function, and representation. Communication and Cognition-Artificial Intelligence 17:111-31.

Bigelow, J. and R.Pargetter. 1987. Functions. Journal of Philosophy 84:181-96.

Boorse, C. 1976a. Wright on functions. Philosophical Review 85:70-86.

. 1976b. What a theory of mental health should be. Journal for the Theory of Social Behavior 6:61-84.

. 1977. Health as a theoretical concept. Philosophy of Science 44:542-73.

1997. A rebuttal on health. In What is Disease?, eds. J. M. Humber and R. F. Almeder, 3-143. Totowa, NJ: Humana Press.

. 2002. A rebuttal on functions. In Functions, eds. A. R. Ariew, R. Cummins, and M. Perlman, 63-112. Oxford: Oxford University Press. 
Caplan, A. 1992. If gene theory is the cure, what is the disease? In Gene Mapping: Using Law and Ethics as Guides, eds. G. Annas and S. Elias, 128-41. New York: Oxford University Press.

Christensen, W. 2012. Natural sources of normativity. Studies in History and Philosophy of Biological and Biomedical Sciences 43:104-12.

Christensen, W. D. and M. H. Bickhard. 2002. The process dynamics of normative function. The Monist 85:3-28.

Collier, J. 2000. Autonomy and process closure as the basis for functionality. Annals of the New York Academy of Sciences 901:280-291.

Cummins, R. 1975. Functional analysis. Journal of Philosophy 72:741-64.

Davidson, D. 1987. Knowing one's own mind. Proceedings and Addresses of the American Philosophical Association 60:441-58.

Davies, P. S. 2001. Norms of Nature. Naturalism and the Nature of Functions. Cambridge, MA: MIT Press.

Delancey, C. 2004. Teleofunctions and oncomice. Environmental Ethics 26:171-88.

- 2006. Ontology and teleofunctions: A defense and revision of the systematic account of teleological explanation. Synthese 150:69-98.

Deplazes, A. 2009. Piecing together a puzzle. EMBO reports 10:428-32.

Douglas, T. and J. Savulescu. 2010. Synthetic biology and the ethics of knowledge. Journal of Medical Ethics 36:687-93.

Engelhardt, H. T. 1986. The Foundations of Bioethics. New York: Oxford University Press.

Ereshefsky, M. 2009. Defining 'health' and 'disease'. Studies in History and Philosophy of Biological and Biomedical Sciences 40:221-7.

Flint. 2012. Protocells: The bottom-up and the top-down approaches in synthetic biology. FlinT [On-line]. Available: http://flint.sdu.dk/index.php?page=protocell (accessed May 5, 2014).

Gibson, D. G., J. I. Glass, C. Lartigue, V. N. Noskov, R. Chuang, M. A. Algire, G. A. Benders, et al. 2010. Creation of a bacterial cell controlled by a chemically synthesized genome. Science 329:52-56.

Godfrey-Smith, P. 1994. A modern history theory of functions. Nô̂s 28:344-62.

Goosens, W. 1980. Values, health, and medicine. Philosophy of Science 47:100-15.

Griffiths, P. E. 1993 Functional analysis and proper functions. British Journal for the Philosophy of Science 44:409-22.

Hanczyc, M. 2011. Structure and the synthesis of life. Architectural Design 81:26-33.

Holm, S. 2012. Biological interests, normative functions, and synthetic biology. Philosophy and Technology. doi: 10.1007/s13347-012-0075-6.

Katsnelson, A. 2010. Researchers start up cell with synthetic genome. Nature [On-line]. Available: $\quad$ http://www.nature.com/news/2010/100520/full/news.2010.253.html (accessed May 5, 2014).

Kendell, R. 1975. The concept of disease and its implications for psychiatry. British Journal of Psychiatry 127:305-15.

Kingma, E. 2010. Paracetamol, poison, and polio: Why Boorse's account of function fails to distinguish health and disease. British Journal for the Philosophy of Science 61:241-64.

Margolis, J. 1976. The concept of disease. Journal of Medicine and Philosophy 1:238-55.

McLaughlin, P. 2001. What Functions Explain-Functional Explanation and Self-reproducing Systems. Cambridge, MA: Cambridge University Press.

Millikan, R. G. 1989. In defense of proper functions. Philosophy of Science 56:288-302. 
1996. On swampkinds. Mind and Language 11:103-17.

Mitchell, S. D. 1995. Function, fitness, and disposition. Biology and Philosophy 10:39-54.

Mossio, M. and A. Moreno. 2010. Organizational closure in biological organisms. History of Philosophy of the Life Sciences 32:269-88.

Mossio, M., C. Saborido, and A. Moreno, 2009. An organizational account of biological function. British Journal for the Philosophy of Science 60:813-41.

Neander, K. 1991. Functions as selected effects: The conceptual analyst's defense. Philosophy of Science 58:168-84.

1996. Swampman meets swampcow. Mind and Language 11:118-29.

O'Malley, M. A., A. Powell, J. F. Davies, and J. Calvert. 2008. Knowledge-making distinctions in synthetic biology. Bioessays 30:57-65.

Preston, C. 2008. Synthetic biology: Drawing a line in Darwin's sand. Environmental Values 17:23-39.

Porcar, M., A. Danchin, V. de Lorenzo, V. A. dos Santos, N. Krasnogor, S. Rasmussen, and A. Moya. 2011. The ten grand challenges of synthetic life. Systems and Synthetic Biology 5:1-9.

Rasmussen, S., M. A. Bedau, L. Chen, D. Deamer, D. C. Krakauer, N. H. Packard, and P. F. Stadler, eds. 2009. Protocells: Bridging Nonliving and Living Matter. Cambridge, MA: MIT Press.

Reznek, L. 1987. The Nature of Disease. London: Routledge \& Kegan Paul.

Saborido, C., M. Mossio, and A. Moreno. 2011. Biological organization and cross-generation functions. British Journal for the Philosophy of Science 62:583-606.

Sandler, R. and L. Simons. 2012. The value of artifactual organisms. Environmental Values 21:43-61.

Scadding, J. 1990. The semantic problem of psychiatry. Psychological Medicine 20:243-8.

Schlosser, G. 1998. Self-re-production and functionality: A systems-theoretical approach to teleological explanation. Synthese 116:303-54.

Schwartz, P. H. 2004. Moving beyond conceptual analysis in the function debate. The Monist $87: 136-53$.

- 2007a. Decision and discovery in defining "disease." In Establishing Medical Reality: Essays in the Metaphysics and Epistemology of Biomedical Science, eds. H. Kincaid and J. McKitrick, 47-64. Dordrecht, The Netherlands: Springer.

- 2007b. Defining dysfunction: Natural selection, design, and drawing a line. Philosophy of Science 74:364-85.

Sedgwick, P. 1982. Psychopolitics. New York: Harper and Row.

Sperber., D. 2007. Seedless Grapes. In Creations of the Mind, eds. E. Margolis and S. Laurence, 124-37. New York: Oxford University Press.

SynBERC. 2012. What is synthetic biology? Synberc [On-line]. Available: http://www.synberc. org/content/articles/what-synthetic-biology (accessed May 5, 2014).

Toepfer, G. 2012. Teleology and its constitutive role for biology as the science of organized systems in nature. Studies in History and Philosophy of Biological and Biomedical Sciences 43:120-32.

Varner, G. 1998. In Nature's Interest. Oxford: Oxford University Press.

Wakefield, J. C. 1992. The concept of mental disorder: On the boundary between biological facts and social values. American Psychologist 47:373-88.

Wright, L. 1973. Functions. Philosophical Review 82:139-68. 